\title{
Influence of energy drinks on acute hemodynamic parameters in young healthy adults: a randomized double-blind placebo-controlled crossover pilot study
}

\author{
Marek Stopa', Mateusz Łobacz², Magdalena Niemczyk33, Karolina Rudowska4 , Agata Radko5, \\ Aleksandra Mikunda', Danuta Czarnecka'1, Agnieszka Olszanecka \\ 1 1st Department of Cardiology, Interventional Electrocardiology, and Hypertension, Institute of Cardiology, Jagiellonian University Medical College, Kraków, Poland \\ 2 Department of Oncology, University Hospital, Kraków, Poland \\ 3 Department of Cardiology, Rydygier Hospital, Kraków, Poland \\ 4 5th Military Hospital with Polyclinic, Kraków, Poland \\ 5 Department of Pulmonology, 5th Military Hospital with Polyclinic in Kraków, Poland \\ 6 St. John Grande Hospital, Kraków, Poland
}

Correspondence to: Agnieszka Olszanecka, MD, PhD, 1st Department of Cardiology, Interventional Electrocardiology, and Hypertension, Institute of Cardiology, Jagiellonian University Medical College, ul. Jakubowskiego 2, 30-688 Kraków, Poland, phone: +48124002150, email: agnieszka.olszanecka@uj.edu.pl Received: January 9, 2020. Revision accepted: March 6, 2020. Published online: March 12, 2020. Kardiol Pol. 2020; 78 (4): 335-337 doi:10.33963/KP.15231 Copyright by the Author(s), 2020
Introduction Energy drinks (ED) contain various substances that act as stimulants: caffeine, taurine, guarana, and ginseng. ${ }^{1}$ They are advertised as mental and physical stimulants and their consumption have increased significantly over the past years. ${ }^{1}$ Cardiovascular adverse effects of EDs have been reported, ${ }^{2}$ but their impact on heart function is still not fully known. Therefore, our aim was to investigate the influence of a single dosage of an ED on acute hemodynamic parameters in young volunteers.

Methods We included volunteers aged between 18 and 30 years, exclusion criteria were: arterial hypertension and other cardiovascular diseases, body weight less than $50 \mathrm{~kg}$, diabetes, thyroid diseases, consumption of more than $250 \mathrm{ml}$ of EDs a week or more than 3 coffees a day, history of caffeine sensitivity or allergy, and pregnancy or breastfeeding. The study was performed from December 2016 to January 2017. All volunteers received comprehensive information about the outline of the experiment and gave written consent to participate. The study was approved by the Bioethics Committee of Jagiellonian University. We conducted a randomized double-blind placebo-controlled crossover study. Each participant attended 2 experimental sessions with a 2 weeks washout period in between. At the first meeting, each participant was randomly assigned to a placebo or ED group using an internet random number generator (www.random.org). At the beginning of each meeting, participants were asked to drink $500 \mathrm{ml}$ of the Rockstar Xdurance Tropical Orange (PepsiCo, Harrison, New York, United States) in 5 minutes. The beverage contained $160 \mathrm{mg}$ of caffeine, $2000 \mathrm{mg}$ of taurine, $50 \mathrm{mg}$ of guarana, $75 \mathrm{mg}$ of carbohydrate, and $0.15 \mathrm{~g}$ of sodium. Total energy of the drink was $320 \mathrm{kcal}$. The placebo, that is, Mirinda (PepsiCo, Harrison, New York, United States), did not differ in color, smell, taste, nor temperature. It contained $64.5 \mathrm{~g}$ of carbohydrate and less than $0.01 \mathrm{~g}$ of sodium with $240 \mathrm{kcal}$ of total energy. Beverage drinking was witnessed by one of the investigators. Drinks were purchased from the funds of the Students' Scientific Group. Participants underwent 4 noninvasive examinations before and after drink consumption. For each person, all procedures were performed in the same sequence and time intervals. Peripheral blood pressure (BP) and heart rate (HR) were measured 15,30 , and 75 minutes from baseline with a standard calibrated automated device, the Omron M3 (Omron, Kyoto, Japan). A 12-lead electrocardiogram was performed 30 minutes from baseline. All echocardiographic measurements were performed by one experienced observer using a digital ultrasound 
system equipped with a $3.5 \mathrm{MHz}$ transducer (GE Vivid 7, General Electric Vingmed Ultrasound, Horten, Norway). At least 3 cardiac cycles were recorded and digitally stored for offline analysis. One experienced observer analyzed the conventional echocardiographic images, using a work station running the EchoPac software version BT11.0.0 (GE Vingmed). The measurement of carotid-femoral pulse wave velocity (PWV) was performed with the use of the SphygmoCor system (Model MM3, software version 6.31; AtCor Medical, Sydney, Australia). Arterial waveforms were obtained with the high-fidelity SPC-301 micromanometer (Millar Instruments, Inc., Houston, Texas, United States) interfaced with a computer running the SphygmoCor software. Arterial PWV was determined by the foot-to-foot flow wave velocity method. ${ }^{3}$

Statistical analysis Data were analyzed with the STATISTICA 12 PL software (StatSoft, Tulsa, Oklahoma, United States). Data distribution was gaussian. Continuous variables were shown as a mean (SD).
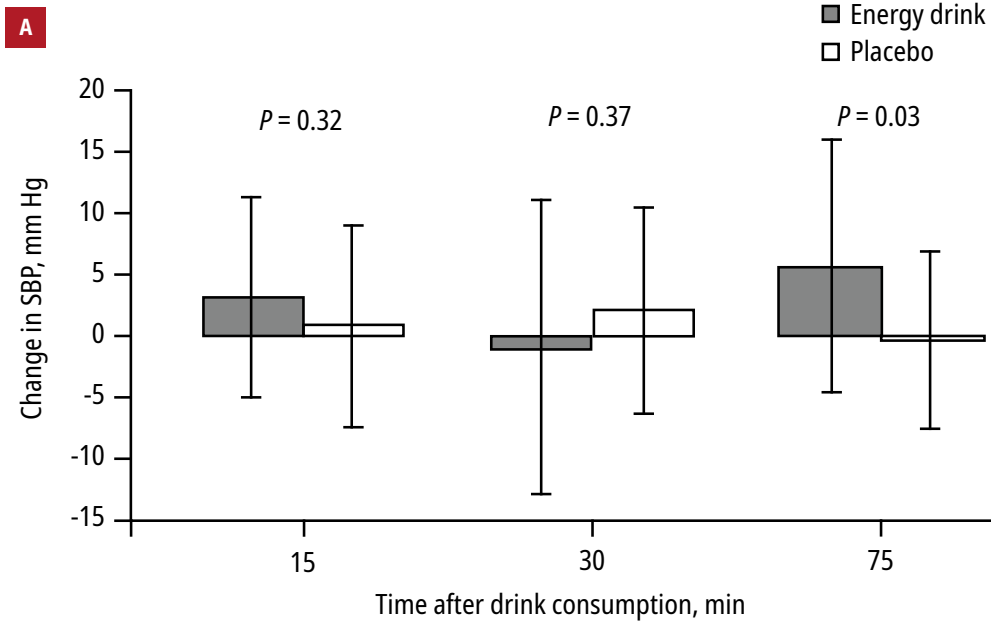

B

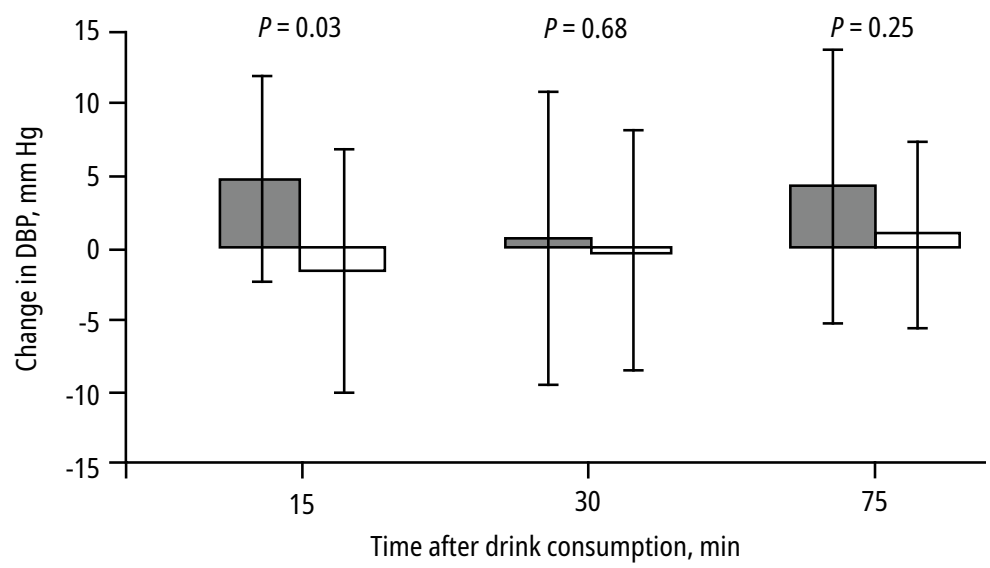

FIGURE 1 Changes in systolic (A) and diastolic (B) blood pressure in 3 time intervals after the consumption of an energy drink or placebo

Abbreviations: DBP, diastolic blood pressure; SBP, systolic blood pressure
The $t$ test for paired data was applied for measures where each participant was its own control, while the unpaired $t$ test was used to compare baseline results. $P$ value of less than 0.05 was considered significant.

Results and discussion A total of 18 healthy young people were included in the study (female sex, 39\%; mean [SD] age, 23.67 [1.19] years; mean [SD] body mass index, $24.67(3.54) \mathrm{kg} / \mathrm{m}^{2}$; smokers, $11 \%)$. Full results of the study are presented in Supplementary material, Table S1. We observed a significant increase in BP 75 minutes after consumption of a single dose of an ED compared with placebo (5.67 vs $-0.33 \mathrm{~mm} \mathrm{Hg}$, respectively; $P=0.03$ ) and increase in diastolic BP 15 minutes after its consumption (4.78 vs $-1.56 \mathrm{~mm} \mathrm{Hg}$, respectively; $P=0.03$ ) (FIGURE $1 A$ and $1 \mathrm{~B}$ ). No significant changes in $\mathrm{HR}$ and electrocardiographic parameters were found. Our findings are similar to that of another study ( $n=25$ ), which used an ED in comparable volume and composition (240 mg of caffeine, $2000 \mathrm{mg}$ of taurine) and observed significant $6.6 \mathrm{~mm} \mathrm{Hg}$ elevation of systolic BP compared with placebo, with no effect on HR. ${ }^{4}$ Further, Phan et $\mathrm{al}^{5}$ found a significant increase in central systolic BP 3 hours after consumption of an ED, while Fletcher et $\mathrm{al}^{6}$ observed only elevation in peripheral BP and did not detect differences in any parameters of central BP measurements. In a study by Szotowska et al, ${ }^{7}$ diastolic BP and HR increased only after a larger dose of an ED (360 mg of caffeine), while for the dose comparable with that used in our experiment (120 mg of caffeine) no change was observed. Discrepancies in results of previous studies on hemodynamic effects of energy drinks may be explained by differences in volume and composition of beverages (mainly caffeine amount), and the time interval between the ED consumption and BP measurements.

Mechanism of the influence of EDs on BP is not clear, and the most widely accepted hypothesis is the activation of the catecholamine pathway. ${ }^{4}$ However, in the available literature, there is no information regarding the hemodynamic profile of the ingredients contained in EDs.

In our study, EDs did not affect any of the echocardiographic parameters, including those analyzed with speckle-tracking echocardiography technique. In a open-label study by Menci et $\mathrm{al},{ }^{8}$ ED consumption was followed by a significant increase in cardiac performance.

Due to the fact that BP is determined by the total peripheral resistance and cardiac output, and the latter is determined by HR and stroke volume, which did not change significantly in our experiment, we hypothesized that the increase in BP was caused by changes in vascular properties. Although not significant, we observed a trend towards the elevation of PWV 
post ED consumption $(P=0.09)$. Pulse wave velocity is the index of vascular elasticity. Dynamic changes of this parameter may reflect peripheral vascular sympathetic function. ${ }^{9}$ Pulse wave velocity is also an independent risk factor of cardiovascular disease as shown in Polish patients..$^{10}$ Changes in BP an PWV may reflect an increase in vascular resistance induced by sympathetic modulation after ED consumption; however, our study with limited number of participants does not allow to draw such a conclusion. Nevertheless, to our knowledge, this is the first study examining the influence of EDs on PWV. Further studies are needed to elucidate the role of endothelial function and autonomic modulation in ED-mediated BP elevation.

In conclusion, our pilot study suggests that a single dose of an ED increases peripheral $\mathrm{BP}$ - both systolic and diastolic - and does not affect $\mathrm{HR}$, central BP, nor cardiac performance. While the increase in BP in our study was mild and would not raise concerns in an acute setting, the sustained elevation of BP at the population level is proven to increase the risk of adverse cardiovascular outcomes. ${ }^{11}$ As there are only few studies on this topic, further investigations are needed to reveal the effect of EDs on $\mathrm{BP}$ and vascular function.

\section{SUPPLEMENTARY MATERIAL}

Supplementary material is available at www.mp.pl/kardiologiapolska.

\section{ARTICLE INFORMATION}

\section{CONFLICT OF INTEREST None declared.}

OPEN ACCESS This is an Open Access article distributed under the terms of the Creative Commons Attribution-NonCommercial-NoDerivatives 4.0 International License (CC BY-NC-ND 4.0), allowing third parties to download articles and share them with others, provided the original work is properly cited not changed in any way, distributed under the same license, and used for noncommercial purposes only. For commercial use, please contact the journal office at kardiologiapolska@ptkardio.pl.

HOW TO CITE Stopa M, Łobacz M, Niemczyk M, et al. Influence of energy drinks on acute hemodynamic parameters in young healthy adults: a randomized double-blind placebo-controlled cross-over pilot study. Kardiol Pol. 2020; 78: 335-337. doi:10.33963/KP.15231

\section{REFERENCES}

1 Reissig CJ, Strain EC, Griffiths RR. Caffeinated energy drinks - a growing problem. Drug Alcohol Depend. 2009; 99: 1-10.

2 Clauson KA, Shields KM, McQueen CE, Persad N. Safety issues associated with commercially available energy drinks. J Am Pharm Assoc. 2008; 48: 55-67.

3 Wojciechowska W, Staessen JA, Nawrot T, et al. Reference values in white Europeans for the arterial pulse wave recorded by means of the SphygmoCor device. Hypertens Res. 2006; 29: 475-483.

4 Svatikova A, Covassin N, Somers KR, et al. A randomized trial of cardiovascular responses to energy drink consumption in healthy adults. JAMA. 2015; 314: 2079-2082.

5 Phan JK, Shah SA. Effect of caffeinated versus noncaffeinated energy drinks on central blood pressures. Pharmacotherapy. 2014; 34: 555-560.

6 Fletcher EA, Lacey CS, Aaron M, et al. Randomized controlled trial of high-volume energy drink versus caffeine consumption on ECG and hemodynamic parameters. J Am Heart Assoc. 2017; 6: e004448.

7 Szotowska M, Bartmańska M, Wyskida $K$, et al. The influence of so called „energy drinks" on the blood pressure and the pulse rate in young, healthy adults. Arter Hypertens. 2013; 17: 169-174.

8 Menci D, Righini FM, Cameli M, et al. Acute effects of an energy drink on myocardial function assessed by conventional echo-Doppler analysis and by speckle tracking echocardiography on young healthy subjects. J Amino Acids. 2013; 2013: 646703 .
9 Nardone M, Incognito A V, Millar PJ. Evidence for Pressure-Independent Sympathetic Modulation of Central Pulse Wave Velocity. J Am Heart Assoc. 2018; 7: e007971.

10 Podolec M, Siniarski A, Pajak A, et al. Association between carotid-femoral pulse wave velocity and overall cardiovascular risk score assessed by the SCORE system in urban Polish population. Kardiol Pol. 2019; 77: 363-370.

11 Lewington S, Clarke R, Qizilbash N, et al. Age-specific relevance of usual blood pressure to vascular mortality: a meta-analysis of individual data for one million adults in 61 prospective studies. Lancet (London, England). 2002; 360: 1903-1913. 